\title{
Promoting Ethics In The Workplace: Why Not Reflect General Organizational Justice?
}

Pablo Ruiz-Palomino, University of Castilla-La Mancha, Spain

Ricardo Martínez-Cañas, University of Castilla-La Mancha, Spain

Raúl del Pozo-Rubio, University of Castilla-La Mancha, Spain

\begin{abstract}
Recent decades reveal increasing academic and practitioner interest in improving corporations' social and ethical reputations. Efforts to promote ethics usually focus on the implementation of explicit, formal mechanisms, aimed at transmitting ethical and moral content and reflecting an interest in behavioural ethics. Although the efficacy of these mechanisms has been demonstrated, such efforts may fail if ethics does not exist in reality in the normal procedures and operations of the firm and in the treatment employees perceive from their employers. Organizational justice is an antecedent of ethical behaviour, though most research depicting this link has centred exclusively on assessing (un)ethical behaviours directed toward the organization. Other insights, however, might suggest a relationship between organizational justice perceptions and general ethical behaviour; therefore, this study conducts an empirical examination of survey data from 436 Spanish banking employees to discern their perceptions of organizational justice by top management and whether these perceptions are related to general ethical/unethical behaviours. Findings, finally, reveal that such perceptions have positive effects on workforce general ethics. That is, actions and efforts by top management that signal organizational justice can help promote ethics among a wider workforce. These findings have substantial practical implications, as well as insights for further research.
\end{abstract}

Keywords: Organizational Justice; Ethical Behaviour; Top Management

\section{INTRODUCTION}

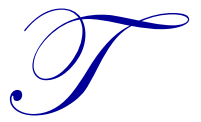

he moral lapses and business scandals in recent decades (e.g., Enron, Arthur Andersen, Health South Corp., Countrywide) and the new issues that seem to arise daily (e.g., allegations of improper contractor payments that forced the resignation of Hewlett-Packard chief executive Mark Herd; Worthen \& Lublin, 2010) make ethics an increasingly salient topic among both academics and practitioners. Academic studies offer substantial contributions to our understanding of the moral behaviour and decision making processes of people in organizational settings (Treviño, 1986; Hunt \& Vitell, 1993; Jones, 1991). Yet the problem of immorality demands constant vigilance to keep it under control, and research still has room to propose solutions and options.

For example, academics have suggested a link between behavioural ethics and justice/fairness perceptions in organizational settings. For decades, these issues were studied only separately, but recent contributions (e.g., Cropanzano \& Stein, 2009) provide strong rationales for their close interconnection, which demands research that can embrace and address this link and thereby advance both organizational justice and behavioural ethics research. Several studies note positive associations between organizational justice variables (i.e., procedures) and behavioural ethics variables (i.e., deviant workplace behaviour) (Cohen-Charash \& Spector, 2001). Yet previous research mostly focuses on a single type of unethical behaviour as a dependent variable, and most of that centres on unethical behaviour directed toward the organization (Treviño \& Weaver, 2001; Rupp \& Bell, 2010). The findings of these studies reflect traditional theoretical rationales (e.g., equity theory; Adams, 1965) that regard unethical responses against the organization (e.g., vandalism, theft) as efforts to balance out perceptions of unfairness that harm employees' interests. Because fairness and justice underlie moral standards and principles (Rawls, 1971), the 
concept clearly can be applied to unethical behaviour directed to any other agent as well. Furthermore, despite the exclusion of organizational justice as an independent contextual variable in previous research (Treviño \& Weaver, 2001), it should play exactly this role, considering its relation to contextual variables such as organizational policies, procedures, and decisions (distributive, procedural justice), as well as interactions with others (interactional justice). Finally, the top management of a firm should exert a strong influence on employees' organizational fairness perceptions.

Therefore, this study aims to analyse the impact of organizational justice on employees' general ethical behaviours. Specifically, we examine the impact of general organizational fairness perceptions, caused by top management actions, on employees' general ethical behaviour. We review prior literature to provide a basis for the rationales we use for our hypothesis. Next, we present our methodology and findings. Finally, we offer some conclusions, limitations, and implications for further research.

\section{THEORETICAL BACKGROUND AND HYPOTHESIS}

According to Treviño and Weaver (2001), justice is a fundamental social expectation that motivates behaviour. When employees perceive fairness or unfairness, they experience certain positive or negative sentiments (e.g., anger, Pillutla \& Murnighan, 1996; satisfaction, Greenberg, 1990; McCain, Tsai, \& Bellino, 2010) that likely influence their consequent behavioural pattern. In line with equity theory (Adams, 1965), in organizational scenarios in which employees perceive general organizational injustice and unfairness, they tend to adjust their behaviour to redress the perceived injustice and also work to improve their welfare or status, usually at the organization's expense (Treviño \& Weaver, 2001). In contrast, when employees face fair treatment, such as when top management fairly allocates resources, employees likely aim to preserve the well-being of their organization (Zoghbi-Manrique de Lara, 2010) and subordinate their own interests to those of their organization (Lind \& Tyler, 1988); their behaviours should also be ethical and in line with the company's expectations (McCain et al., 2010). The prevalence of unethical behaviours directed against the company's interests in recent decades (Greenberg, 2002) thus may be understood according to this "seeking balance" rationale, which is also consistent with the Van den Boss, Lind, and Wilde's (1997) idea that a broad fairness heuristic guides people's thinking about their relationship with their organizations, in terms of commitment and support dimensions (Treviño \& Weaver, 2001).

Although previous research mostly assesses unethical behaviours exclusively directed to the organization in contexts in which employees perceive organizational unfairness, there is strong evidence that people also value moral principles, such as justice, for their own sake (Cropanzano \& Stein, 2009), not just in relation to the damage caused or benefits received. For example, Turillo, Folger, Lavelle, Umphress, and Gee (2002) suggest that selfinterest is not the only, or even the prime, motivator for people to attend to fairness issues. Rather, employees may perceive that the virtue of fairness is its own reward (Turillo et al., 2002; Gillespie \& Greenberg, 2005), in support of the idea that individuals present endogenous deontic emotions (Turillo et al., 2002). Moral values also appear beneficial for their own sake, as human ideals (González \& Guillén, 2008), toward which people naturally strive (Kreeft, 1990). Because justice thus constitutes an important part of the larger domain of morality and virtuousness (Cropanzano, Byrne, Bobocel \& Rupp, 2001; Folger, Cropanzano \& Goldman, 2005), people who perceive justice in their organizational settings may feel more fairly treated and appreciated (Argandoña, 2011), which ultimately could motivate reciprocity in the form of fairness and other morally virtuous behaviours (Cameron, Bright, \& Caza, 2004). Thus, general ethical behaviour, one which entails acts not exclusively directed toward the organization, could be enhanced in situations that encourage perceptions of organizational fairness. Prior business ethics studies (Zabid \& Alsagoff, 1993) cite the important impact of top management for determining the level of ethics among employees, arguing that an ethics gap at top management levels prevents an ethical workforce from emerging (Gini, 1997). Fairness also is an issue that Treviño, Hartman, and Brown (2000) defend as crucial for ethics and for effective ethical leadership, which in line with previous research (Peterson, 2004) can enhance ethical behaviour in organizational settings. Accordingly, we assert that perceived general organizational justice, in reference to the perceived fairness exhibited by top management, has a positive impact:

Hypothesis 1: General organizational justice, as manifested in top management fairness, relates positively to employees' general ethical behaviour. 


\section{METHODOLOGY}

\section{Sample and Procedure}

The survey was distributed to 4,136 employees of large branches or offices of various Spanish banking companies. The questionnaires typically were distributed directly to employees, after gaining the consent of the branch manager; in some cases, they were mailed to employees, with the approval of a regional director. The 436 usable surveys finally received represented a response rate of $10.5 \%$, which is reasonable for organizational behaviour research, especially considering that the employees represented multiple business organizations (Valentine, Greller, \& Richtermeyer, 2006).

To minimise apprehension and social desirability bias, the cover letter to the questionnaire emphasised that there were no right or wrong answers. Wording in the questionnaire itself also guaranteed absolute anonymity and confidentiality to participants.

To evaluate the possibility for nonresponse bias, the first and last quartiles of submissions were compared; late respondents should be more similar to nonrespondents than early ones (Armstrong \& Overton, 1977). The chisquare and independent sample t-tests conducted did not reveal any significant differences in the study variables, so non response bias did not appear to be a concern for our study.

\section{Measures}

To measure general organizational justice, we used three items adapted from Treviño and Weaver's (2001) scale, using a five-point response format $(1=$ strongly disagree, $5=$ strongly agree). Instead of organization though, we used top management as our main focus or responsible agent, which supported our research goal of determining the role of top management behaviour in influencing employees' ethical/unethical behaviours. In general, the items address the extent to which employees perceive that they are treated fairly and respectfully, as well as how fairly top management acts with regard to employees' interests (e.g., In general, top management treats its employees fairly).

Guided by previous research on business ethics (Treviño \& Weaver, 2001; Treviño, Butterfield \& McCabe, 1998), we assessed perceived ethical behaviour by asking respondents about any unethical behaviours they had perceived by peers in the organizational setting. By asking about peers' unethical conduct, we mitigate the potential for social desirability bias (Treviño \& Weaver, 2001; Treviño et al., 1998). Three behavioral items were adapted from previous research (e.g. Izraeli, 1988; Treviño \&Weaver, 2001; Peterson, 2004) which as in Peterson (2004) encompassed a variety of possible ethical failures with implications for the organization, co-workers and customers (e.g. misuse of company materials, claiming credit for someone else work, exaggerating benefits and advantages of corporate products and services). With a five-point response format $(1=$ never, $5=$ very often $)$, respondents indicated the level of frequency of such acts; the responses were reverse scored and averaged, so higher values represented more ethical behaviour perceived.

\section{Data Analysis}

We used SPSS (v.19.0) statistical software to generate descriptive statistics and other statistical analyses of the data. A correlation analysis and an independent two-sample t-test help test the hypothesis. As Table I reveals, the internal reliability of the measures was sufficient. The Cronbach's alpha coefficient for the dependent variable was slightly lower than the minimum level of 0.7 recommended by Nunnally (1978) for basic research, but additional statistical analyses (i.e., a single factor for three items and acceptable item correlation with respect to the scale's corrected total) revealed the appropriateness of the measure. In addition, levels higher than 0.60 can be considered acceptable, especially for exploratory scales (Hair, Black, Babin \& Tatham, 2006). 
Table I

Means, deviations, and correlation matrix. (Cronbach's alpha in bold. $\mathrm{N}=434$ )

\begin{tabular}{|l|c|c|c|c|}
\hline & Mean & $S D$ & 1 & 2 \\
\hline 1. Perceived ethical behaviour & 3.55 & .78 &. $\mathbf{6 1}$ & \\
\hline 2. General organizational justice & 2.88 & .89 & $.23^{* *}$ & $\mathbf{. 8 6}$ \\
\hline
\end{tabular}

Notes: The diagonal represents the Cronbach's alpha. Off-diagonal elements are the correlations between the variables. $* *$ Significant at the .01 level (one-tailed)

\section{RESULTS}

\section{Hypothesis Testing}

We performed correlation analysis to test the strength and direction of the linear relationships among the target variables in this study: perceived ethical behaviour and general organizational justice. In Table I, we provide the results, which indicate some preliminary support for the hypothesis, in that the association between general organizational justice and perceived ethical behaviour $(\mathrm{r}=.23)$ is significant at $p<.01$, and in the predicted direction.

Table II

General organizational justice and perceived ethical behaviour (Independent two-sample t-test)

\begin{tabular}{|c|c|c|c|c|c|c|c|}
\hline \multirow[t]{2}{*}{. } & \multicolumn{2}{|c|}{$\begin{array}{l}\text { High top management } \\
\text { general justice }(n=234)\end{array}$} & \multicolumn{2}{|c|}{$\begin{array}{l}\text { Low top management } \\
\text { general justice }(n=200)\end{array}$} & \multirow[b]{2}{*}{$t$-statistic } & \multirow[b]{2}{*}{$\begin{array}{c}p \text {-value } \\
\text { CI }_{95}\end{array}$} & \multirow[b]{2}{*}{$\mathrm{CI}_{95}$} \\
\hline & $M$ & $S D$ & $M$ & $S D$ & & & \\
\hline $\begin{array}{l}\text { Perceived ethical } \\
\text { behaviour }\end{array}$ & 3.71 & .73 & 3.35 & .80 & 4.757 & $.00 * *$ & $.21-.50$ \\
\hline
\end{tabular}

** Significant at the .01 level (one-tailed)

To reinforce those results, we also conducted an independent two-sample t-test to determine if the means of two different populations (i.e., those who perceived high versus low general organizational justice) differ statistically in terms of perceived ethical behaviour. As the results in Table II reveal, and in line with our previous results, the test is significant at the .01 level, $t(432)=4.757$. Thus, employees who perceive that top management's general justice is high $(M=3.71, S D=.73, \mathrm{n}=234)$ on average represent a more ethical workforce than the group that perceives top management's general justice as low $(M=3.35, S D=.80, \mathrm{n}=200)$. In addition, with $95 \%$ confidence, we assert that there is always a mean difference between the two conditions related to the hypothesis, ranging between .21 and .50 , which indicates significant differences (in the predicted direction) in the mean level of the perceived ethical behaviour measure, according to the extent to which top management shows general organizational justice in its daily behaviours.

In summary, both the correlation analysis and the independent two-sample t-test offer support for our proposed hypothesis. Thus, general organizational justice, as perceived in the top management sphere, has an important, positive effect on workforce ethics.

\section{DISCUSSION}

This investigation has aimed to analyse the role of general organizational justice perceptions, specifically those derived from reflections on the fairness of the treatment and conduct of top management, in determining the ethical behaviour of employees. Consistent with our hypothesis, we find that general organizational justice has a significant positive effect on employees' ethical behaviours, spanning actions directed toward the organization, coworkers, and customers. Therefore, our findings extend prior research that positively link various measures of perceived organizational unfairness to the unethical conduct of employees that harms the organization (Greenberg, 1990; Treviño \& Weaver, 2001; Cohen-Charash \& Spector, 2001; Rupp \& Bell, 2010), likely as a result of experiencing negative emotions (e.g., frustration, anger) in such an unfair organizational scenario (Skarlicki \& Folger, 1997). 
Perhaps even more important, this investigation adds to previous research on organizational justice and behavioural ethics by finding a positive relationship between general organizational justice perceptions and an ethical behaviour measure that encompasses actions directed to the organization, co-workers, and customers. Although recent research suggests that organizational justice perceptions (procedural and distributive) positively affect employees' ethical behaviour in their interactions with customers (McCain et al., 2010), our measure of ethical behaviour adds conduct directed specifically toward customers or co-workers. In addition to affecting ethical behaviours directed toward the organization, general organizational fairness perceptions can influence employees' ethical behaviours in general. If they perceive that managers, i.e. top management, offers fair conduct and treatment, employees likely feel positive emotions and reciprocate by treating others in a fair and ethical manner (McCain et al., 2010).

Efforts to build ethical leadership at the top levels thus are highly salient for management practitioners interested in promoting organizational ethics. Considering their high formal authority, top managers exert significant influence through their beliefs, features, decisions, and actions (Merton, 1957). Fairness and justice behavioural dimensions are expected in people who are perceived as effective ethical leaders (Treviño et al., 2000) and who have moral principles (Folger et al., 2005). Therefore top management cannot ignore this dimension in their daily working life if they hope to exert a positive impact on employees' ethical behaviours.

Several limitations in this study should be considered as well. In particular, this research took place in a single industry setting (banking) and a specific cultural context (Spain), so though the results likely hold in similar contexts, the external validity of our results may be somewhat limited. Furthermore, we measured ethical behaviour by asking respondents about their co-workers' perceived unethical behaviours in organizational settings. This measure helps reduce social desirability bias (Treviño \& Weaver, 2001; Treviño et al., 1998), but we might have missed out on more accurate information about the real impact that organizational fairness perceptions have on a respondent's own ethical behaviour. Finally, our study is limited in that it focuses on just the direct relationship between organizational justice and behavioural ethics, without accounting for other potential intervening (mediating or interacting) variables within that relationship.

We thus see many interesting directions for further research to provide insights into this organizational justice-behavioural ethics relationship. First, studies that pertain to other industries and cultural contexts should be conducted to determine the generalisability of our findings. Second, additional research might analyse the role of other variables in the relationship. As we noted, because feelings of inequity or equity tend to produce negative (e.g., frustration, anger; Coughlan \& Connolly, 2001) or positive emotions and attitudes respectively (job satisfaction; Greenberg, 1990; McCain et al., 2010), general organizational fairness perceptions might influence employees' (un)ethical conduct through the effect of such emotional and attitudinal variables. Researchers could seek to ascertain if these variables really play a mediating role or simply represent a final outcome of the relationship. Third, and finally, personal variables, such as cognitive moral development, could interact and help explain this relationship (Cropanzano \& Stein, 2009), so further studies aimed at providing insights into the complex nature of this relationship might take into account the influence of personality traits.

\section{AUTHOR INFORMATION}

Pablo Ruiz-Palomino is an Associate Professor of Business Administration at UCLM, Spain. He received a Ph.D. in Business Administration; his current research interests focus on business ethics and social capital. E-mail: Pablo.Ruiz@uclm.es (Corresponding author)

Ricardo Martinez-Cañas is an Associate Professor of Business Administration at UCLM, Spain. He received a Ph.D. in Business Administration; his current research interests include business ethics, social capital, and strategy. E-mail: Ricardo.Martinez@uclm.es

Raul del Pozo-Rubio is an Assistant Professor of Business Administration at UCLM, Spain. He is also a doctoral candidate in Economics and Finance, and his current research interests are focused on long-term care costs and financing, as well as tourism and the environment. E-mail: Raul.delpozo@uclm.es 


\section{REFERENCES}

1. Adams, J.S. (1965). Inequity in Social Exchange. In Berkowitz, L. (Ed.), Advances in Experimental Social Psychology: Volume 2, New York: Academic Press.

2. Argandoña, A. (2011). Beyond Contracts: Love in Firms. Journal of Business Ethics, 99, 77-85.

3. Armstrong, J. S. \& Overton, T.S. (1977). Estimating Non Response Bias in Mail Surveys. Journal of Marketing Research, 14, 396-403.

4. Cameron, K., Bright, D. \& Caza, A. (2004). Exploring the relationships Between Organizational Virtuousness and Performance, American Behavioural Scientist 47 (6), 1-24.

5. Cohen-Charash, Y. \& Spector, P.E. (2001). The Role of Justice in Organizations: A Meta-Analysis, Organizational Behavior and Human Decision Processes, 86, 278-321.

6. Coughlan, R. \& Connolly, T. (2001). Predicting Affective Response to Unexpected Outcomes. Organizational Behaviour and Human Decision Processes, 85, 211-225.

7. Cropanzano, R., Byrne, Z. S., Bobocel, D. R., \& Rupp, D. E. (2001). Moral Virtues, Fairness Heuristics, Social Entities, and Other Denizens of Organizational Justice, Journal of Vocational Behavior, 58, 164209.

8. Cropanzano, R. \& Stein, J.H. (2009). Organizational Justice and Behavioral Ethics: Promises and Prospects, Business Ethics Quarterly, 19, 193-233.

9. Folger, R., Cropanzano, R. \& Goldman, B. (2005) What is the Relationship between Justice and Morality? In Greenberg J. \& Colquitt J.A. (Eds.): Handbook of Organizational Justice, Mahwah: Lawrence Erlbaum Associates

10. Gillespie, J.Z. \& Greenberg, J. (2005). Are Goals of Organizational Justice Self-Interested?. In Greenberg J. \& Colquitt J.A. (Eds.): Handbook of Organizational Justice, Mahwah: Lawrence Erlbaum Associates.

11. Gini, A. (1997). Moral Leadership and Business Ethics. Journal of Leadership and Organizational Studies, 4, 64-81.

12. Gónzalez, T. F. \& Guillén, M. (2008), Organizational Commitment: A Proposal for a Wider Ethical Conceptualization of Normative Commitment', Journal of Business Ethics, 78, 401-414.

13. Greenberg, J. (1990). Organizational Justice; Yesterday, Today and Tomorrow, Journal of Management, $16,399-432$.

14. Greenberg, J. (2002). Who stole the Money and When?: Individual and Situational Determinants of Employee Theft, Organizational Behaviour and Human Decision Processes, 89, 985-1003.

15. Hair, J.F. Jr., Black, W.C., Babin, B.J., Anderson, R.E., \& Tatham, R.L. (2006). Multivariate Data Analysis. (6 ${ }^{\text {th }}$ Ed.). New Jersey: Prentice Hall International.

16. Hunt, S.D. \& Vitell, S. (1993). The General Theory of Marketing Ethics: A Retrospective and Revision. In Smith N.C. \& John A. Q. (Eds.): Ethics in marketing. Homewood, IL: Irwin Inc.

17. Izraeli, D. (1988). Ethical Beliefs and Behaviour among Managers: A Cross-Cultural Perspective, Journal of Business Ethics, 7, 263-271.

18. Jones T.M. (1991). Ethical Decision Making by Individuals in Organizations: An Issue-Contingent Model. Academy of Management Review, 16, 366-395.

19. Kreeft, P. (1990). A Summa of the Summa. San Francisco, CA: Ignatius Press.

20. Lind, E.A. and Tyler, T.R. (1988). The Social Psychology of Procedural Justice, New York: Plenum Press.

21. McCain, S-L Ch., Tsai, H. \& Bellino, N. (2010). Organizational Justice, Employees' Ethical Behavior, and Job Satisfaction in the Casino Industry, International Journal of Contemporary Hospitality Management, 22, 992-1009.

22. Merton, R.K. (1957). The Role-Set. British Journal of Sociology, 8, 106-120.

23. Nunnally, J. (1978). Psychometric Theory, 2nd Edition, New York: McGraw-Hill.

24. Peterson, D.K. (2004). Perceived Leader Integrity and Ethical Intentions of Subordinates. The Leadership \& Organization Development Journal, 25, 7-23.

25. Pillutla, M. \& Murnighan, P. (1996). Unfairness, Anger and Spite: Emotional Rejections of Ultimatum Offers', Organizational Behaviour and Human Decision Processes, 68, 208-224.

26. Rawls, J. (1971). A Theory of Justice. Cambridge: Harvard University Press.

27. Rupp, D.E. \& Bell, C. (2010). Retribution, Moral Self Regulation and Self Interest in the Decision to Punish: A Moral Motives Extension of the Deontic Model of Justice, Business Ethics Quarterly, 20, 89106. 
28. Skarlicki, D.P. \& Folger, R. (1997). Retaliation in the Workplace: The Roles of Distributive, Procedural, and Interactional Justice. Journal of Applied Psychology, 82, 434-443.

29. Treviño, L.K. (1986). Ethical Decision Making in Organizations: A Person-Situation Interactionist Model. Academy of Management Review, 11, 601-617.

30. Treviño, L.K, Butterfield, K.D. \& McCabe, D.L (1998). The Ethical Context in Organizations: Influences on Employee Attitudes and Behaviour. Business Ethics Quarterly, 8, 447-476.

31. Treviño, L.K., Hartman, L. P. \& Brown, M. (2000). Moral Person and Moral Manager: How Executives Develop a Reputation for Ethical Leadership. California Management Review, 42, 128-142.

32. Treviño, L. K. \& Weaver, G. (2001). Organizational Justice and Ethics Program 'Follow Through': Influences on Employees Harmful and Helpful Behaviour, Business Ethics Quarterly 11(4), 651-671.

33. Turillo, C. J., Folger, R., Lavelle, J. J., Umphress, E. E., \& Gee, J. O. (2002). Is Virtue its Own Reward? Self-Sacrificial Decisions for the Sake of Fairness. Organizational Behavior \& Human Decision Processes, 89, 839-865.

34. Valentine, S., Greller, M.M. \& Richtermeyer, S. (2006). Employee Job Response as a Function of Ethical Context and Perceived Organization Support. Journal of Business Research 59 (5), 582-588.

35. Van den Boss, K., Lind, E.A. \& Wilde, H.A. (1997). The Psychology of Procedural and Distributive Justice Viewed from the Perspective of Fairness Heuristic Theory. In Cropanzano R. (Ed.), Justice in the workplace, Volume 2: From Theory to practice. Mahwah, NJ: Erlbaum.

36. Worthen, B. \& Lublin, J. S. (2010). Mark Hurd Neglected to Follow H-P code, The Wall Street Journal, August 9, pp. B1-B5.

37. Zabid, A.R.M. \& Alsagoff, S.K. (1993). Perceived Ethical Values of Malaysian Managers. Journal of Business Ethics, 12, 331-337.

38. Zoghbi-Manrique de Lara, P. (2010). Do Unfair Procedures Predict Employees' Ethical Behavior by Deactivating Formal Regulations?. Journal of Business Ethics, 94, 411-425. 


\section{NOTES}

